\title{
Elementos melódicos e harmônicos recorrentes em Notas Irresponsáveis de Bruno Kiefer: uma abordagem Pós- Tonal
}

\author{
Recurring melodic and harmonic elements in Bruno Kiefer's Notas \\ Irresponsáveis: a Post-Tonal approach
}

\author{
Vinicius Dias Prates \\ Universidade Federal do Rio Grande do Sul
}

Resumo: Este trabalho apresenta um estudo analítico dos componentes melódicos e harmônicos de Notas Irresponsáveis (1986/87) para trio de flautas transversais de Bruno Kiefer (1923-1987). Utilizamos o livro Introduction to Post-Tonal Theory de Joseph N. Straus (2005) como referencial teórico com o objetivo de nos embasar na Teoria Pós-Tonal. Delimitamos os conjuntos melódicos e harmônicos de Notas Irresponsáveis tendo como critério parâmetros motívicos e texturais presentes na obra. Uma vez identificados os agrupamentos sonoros e analisados conforme com a Teoria Pós-Tonal, buscamos categorizá-los de acordo com suas ocorrências em cada uma das seções da composição. Entre os conjuntos mais recorrentes observamos a presença de formações octatônicas, cromáticas e pseudo-cromáticas além de agrupamentos com características diatônicas. Através dos resultados de nossas análises, procuramos entender quais são os elementos melódicos e harmônicos característicos do compositor, bem como encontrar traços em comum entre a peça escolhida para este artigo e o repertório investigado por Gerling (2001) e Mayer (2005), autores que estudaram a obra de Kiefer sob a ótica Pós-Tonal. Verificamos que, assim como em nossa literatura de apoio, os componentes octatônicos, agrupamentos em terças menores e trítonos surgem como elementos preferenciais do compositor em Notas Irresponsáveis. Observamos que, assim como demonstrado nos estudos de Mayer (2005), a terça menor se apresenta como componente de autocitação no trio de flautas de Kiefer.

Palavras-chave: Bruno Kiefer; Elementos Melódicos e Harmônicos; Teoria Pós-Tonal; Flauta transversal

\begin{abstract}
This paper is an analytical study of the melodic and harmonic elements present in Notas Irresponsáveis (1986/87) for flute trio by Bruno Kiefer (1923-1987). We used the book Introduction to Post-Tonal Theory by Joseph N. Straus (2005) as a theoretical framework with the objective of basing ourselves on the Post-Tonal Theory. We delimited the melodic and harmonic sets of Notas Irresponsáveis taking motivic and textural parameters presents in the work as criterion. Once the sets have been identified and analyzed according to the Post-Tonal Theory, we tried to categorize
\end{abstract}


PRATES, V. D. Elementos melódicos e harmônicos recorrentes em Notas Irresponsáveis de Bruno Kiefer: uma abordagem Pós-Tonal

them according to their occurrence in each of the piece sections. We observed the presence of octatonic, chromatic and pseudo-chromatic formations, as well as sets with diatonic characteristics among the most recurrent sets. Through the results of our analysis, we tried to understand the composer's melodic and harmonic characteristics, as well as to find common traits between the work chosen for this article and the elements investigated by Gerling (2001) and Mayer (2005), authors who studied Kiefer's work from a Post-Tonal perspective. We found that, just as in our support literature, the octatonic components, as well as minor thirds and tritones sets, appear as the composer's preferential elements in Notas Irresponsáveis. We observed that, as demonstrated in Mayer's studies, the third minor presents itself as a self-citation element in Kiefer's flute trio.

Keywords: Bruno Kiefer; Melodic and Harmonic Elements; Post-Tonal Theory; Flute

Este artigo é parte integrante de um estudo que busca identificar os traços característicos da escrita para flauta transversal de Bruno Kiefer (1923-1987) (Prates, Winter e Carvalho (2014), Prates (2015), Prates (2017) e Prates e Winter 2018)). Aqui é exposta uma análise dos elementos melódicos e harmônicos encontrados em Notas Irresponsáveis (1986/87) para trio de flautas transversais. Buscamos traçar paralelos entre a peça escolhida e a literatura analítica da obra de Kiefer que nos permitissem identificar a familiaridade estética de Notas Irresponsáveis com o repertório do compositor já investigado por Gerling (2001) e Mayer (2005). Nosso objetivo foi encontrar em Notas Irresponsáveis a possível recorrência dos elementos melódicos e harmônicos identificados por esses autores utilizando a Teoria Pós-Tonal proposta por Straus (2005) no livro Introduction to Post-Tonal Theory.

\section{O Referencial teórico}

A fim de analisar e compreender os elementos melódicos e harmônicos adotados pelo compositor em Notas Irresponsáveis, utilizamos como referencial teórico a obra Introduction to Post-Tonal Theory de Joseph N. Straus (2005). A Teoria Pós-Tonal tem como princípio a utilização de números em substituição a nomes de notas e classificação de intervalos. A seguir, apresentamos conceitos importantes para o entendimento da teoria segundo Straus (2005):

- Notação Numérica: ao tratarmos notas com nomes diferentes mas mesma frequência ${ }^{1}$ chegamos ao número de 12 sons diferentes.

\footnotetext{
${ }^{1}$ Equivalência Enarmônica conforme Straus (2005).
} 
MUSICA THEORICA Revista da Associação Brasileira de Teoria e Análise Musical 2019, v. 4, n. 1, p. 255-279-Journal of the Brazilian Society for Music Theory and Analysis@ TeMA 2019 - ISSN 2525-5541

Dessa forma, a cada som será atribuído um número em substituição de sua nomenclatura tradicional conforme o quadro abaixo:

\begin{tabular}{|c|c|}
\hline Notação Numérica & Classe de Nota e Equivalência Enarmônica \\
\hline 0 & Si $¥$, Dó, Réb, \\
\hline 1 & Dó\#, Réb \\
\hline 2 & Dó*, Ré, Mi bb \\
\hline 3 & Ré\#, Mi \\
\hline 4 & Ré*, Mi, Fáb \\
\hline 5 & Mi $\#$, Fá, Sol \\
\hline 6 & Fá\#, Solb \\
\hline 7 & Fá*, Sol, Lábl \\
\hline 8 & Sol\#, Láb \\
\hline 9 & Sol*, Lá, Si b, \\
\hline 10 & Lá\#, Si, \\
\hline 11 & Lá», Si, Dób \\
\hline
\end{tabular}

Quadro 1: notações numéricas das classes de notas

- Classe de Intervalo: representação numérica atribuída ao intervalo na sua formação mais simples. Não são levados em consideração intervalos compostos, sendo entendidos como sons integrantes dentro de uma oitava. Também podem ser consideradas as inversões de intervalos superiores a 6 semitons (trítono) como por exemplo: Dó-Si = sétima maior, intervalo 11 (semitons) é considerado Si-Dó, Classe de Intervalo 1 (semitom).

Straus (2005) comenta que o tipo de Notação de Intervalo que adotaremos depende do tipo de análise que pretendemos realizar. Dessa forma, para essa pesquisa adotamos classificações intervalares que se encaixem no espaço de uma oitava levando em consideração a inversão, conforme quadro abaixo:

\begin{tabular}{|l|l|}
\hline Notação Numérica & Classe de Intervalos \\
\hline 0 & oitava, uníssono \\
\hline 1 & segunda menor \\
\hline 2 & segunda maior, terça diminuta \\
\hline 3 & segunda aumentada, terça menor \\
\hline
\end{tabular}


PRATES, V. D. Elementos melódicos e harmônicos recorrentes em Notas Irresponsáveis de Bruno Kiefer: uma abordagem Pós-Tonal

\begin{tabular}{|l|l|}
\hline 4 & terça maior, quarta diminuta \\
\hline 5 & terça aumentada, quarta justa \\
\hline 6 & quarta aumentada, quinta diminuta \\
\hline 5 & quinta justa (invertida) \\
\hline 4 & quinta aumentada, sexta menor (invertidas) \\
\hline 3 & sexta maior, sétima diminuta (invertidas) \\
\hline 2 & sexta aumentada, sétima menor (invertidas) \\
\hline 1 & sétima maior (invertida) \\
\hline
\end{tabular}

Quadro 2: notações numéricas das classes de intervalos e inversões

Conjunto de Classe de Notas, que chamaremos de Conjunto de Notas ou simplesmente Conjunto: ao analisarmos uma peça, identificamos as Classes de Notas que compõe algum trecho e agrupamos de maneira a formar um conjunto (coleção) de sons que pode possuir muitas maneiras diferentes de agrupamento ou ordenamento. Portanto, uma vez identificado os sons (Classe de Notas), devemos ordenar o conjunto na sua Forma Normal, que é sua configuração intervalar mais compacta da esquerda para a direita (vide também Forte (1973)), ou seja, observando o espaço ascendente dentro de uma oitava, sempre com o menor intervalo entre a primeira e a última Classe de Nota.

Straus (2005) traz exemplos de inversões e transposições de conjuntos a partir de uma determinada Classe de Nota para outra. Isso possibilita que vários outros conjuntos surjam em decorrência de um e estabelecendo entre eles uma identidade intervalar, o que se chama Classe de Conjuntos. Contudo, não utilizamos esse procedimento nessa pesquisa. Buscamos apenas as transposições de conjuntos a fim de iniciar com a Classe de Notas 0 (Dó), chamada de Forma Prima, pois assim tivemos a possibilidade de verificar mais facilmente a disposição intervalar do conjunto, nos remetendo à lista de Classes de Conjuntos segundo Forte (1973) que Straus (2005) apresenta no final do livro.

Uma vez entendidos esses conceitos, trouxemos como ferramenta de auxílio o programa PC Set Calculator, ${ }^{2}$ desenvolvido em 2001 por David Walters. Ao inserir dados numéricos relacionados aos sons o aplicativo calcula as Formas Normais e Primas, bem como fornece a classificação dos conjuntos segundo Forte (1973). Após as análises da peça, delimitamos os conjuntos encontrados por meio do programa e identificamos por parênteses as Formas Normais e Formas Primas

\footnotetext{
2 Disponível na internet em http://www.mta.ca/faculty/arts-letters/music/pc-set_project/calculator/ pc_calculate.html\#.
} 
MUSICA THEORICA Revista da Associação Brasileira de Teoria e Análise Musical 2019, v. 4, n. 1, p. 255-279-Journal of the Brazilian Society for Music Theory and Analysis @ TeMA 2019 - ISSN 2525-5541

desses agrupamentos utilizando Notação Numérica e os nomeamos de acordo com Forte (1973) através de colchetes.

\section{Metodologia}

A metodologia se guiou por análises que buscaram identificar os elementos melódicos e harmônicos recorrentes em Notas Irresponsáveis. Seguindo os conceitos propostos por Straus (2005), adotamos os seguintes passos: identificação de conjuntos presentes na obra classificando-os em suas Formas Normais e Formas Primas e categorizando-os na nomenclatura segundo Forte (1973); cruzamento de dados com o objetivo de compreender uma possível identidade temática presente entre Notas Irresponsáveis e outras obras de Kiefer já analisadas por Gerling (2001) e Mayer (2005). Estes autores embasam seus dados conforme a Teoria-Pós Tonal. Por esta razão, optamos pela mesma ferramenta de análise a fim de aproximar nossos resultados à linguagem adotada por estes autores.

Devido à ausência de registro sonoro da obra que escolhemos para esse artigo, realizamos uma gravação da mesma a fim de auxiliar no processo de análise. É possível conferir o registro através do link https://soundcloud.com/ vinicius-prates-7/notas-irresponsaveis-bruno-kiefer. A gravação que disponibilizamos tem o objetivo de auxiliar o leitor na compreensão das ideias explanadas neste trabalho, e por ter sido realizada paralelamente ao nosso processo de análise deve ser entendida como um referencial sonoro de apoio sem fins interpretativos e/ou performáticos. Os resultados de nossas investigações contribuíram para o melhor entendimento dos materiais propostos por Kiefer, nos permitindo relacioná-los de forma interpretativa e agregar coerência e sentido aos parâmetros melódicos e harmônicos.

\section{Notas Irresponsáveis (1986/87): abordagem analítica}

Nesta análise utilizamos o termo Seção para designar os trechos musicais de maiores dimensões e que apresentem ideias completas com início, meio e fim. O termo Região temática, ou simplesmente região é utilizado para destacar os trechos que apresentem melodias, fragmentos melódicos e/ou motivos que, em combinação, configurem pequenas ideias musicais. 
PRATES, V. D. Elementos melódicos e harmônicos recorrentes em Notas Irresponsáveis de Bruno Kiefer: uma abordagem Pós-Tonal

Notas Irresponsáveis possui estrutura dividida em três seções distintas na forma ABA'. A Seção $A$ possui três regiões temáticas (" $a$ ", " $b$ " e “c") com 11, 17 e 24 compassos respectivamente. A Seção B é formada por quatro regiões temáticas (" $d$ ", " $e$ ", “ $d$ " " e "f"). A região $d$, em forma de cânone possui 9 compassos; a região e, espécie de recapitulação de motivos já apresentados, totaliza 9 compassos; $d$ 'é um desenvolvimento do cânone anterior com 26 compassos; a região $f$ possui material novo de caráter coral em 10 compassos. A Seção $A^{\prime}$ apresenta duas regiões temáticas, sendo $a^{\prime}$ uma recapitulação do início da obra totalizando 13 compassos, seguida de uma Coda de 5 compassos.

\begin{tabular}{|c|c|c|}
\hline \multirow{3}{*}{ Seção A (c. 1-52) } & região a (11 compassos) & c. $1-11$ \\
\hline & região b (17 compassos) & Anacruse para c. $12-28$ \\
\hline & região c (24 compassos) & c. $29-52$ \\
\hline \multirow{4}{*}{$\begin{array}{c}\text { Seção B (anacruse para c. 53- } \\
116)\end{array}$} & região d (9 compassos) & Anacruse para c. 53-62 \\
\hline & região e (9 compassos) & 2 depois de $60-10$ depois de $60^{3}$ \\
\hline & região d' (26 compassos) & $\begin{array}{l}\text { Anacruse para } 11 \text { depois de c. } 60-65 \\
\text { depois de } 100\end{array}$ \\
\hline & região f (10 compassos) & 6 depois de 100 - c. 116 \\
\hline \multirow{2}{*}{ Seção A' (c. 117-134) } & região a' (13 compassos) & c. $117-129$ \\
\hline & Coda (5 compassos) & c. $130-134$ \\
\hline
\end{tabular}

Quadro 3: Notas Irresponsáveis; forma

Sobre a escrita, Notas Irresponsáveis apresenta características de notação tradicional no que se refere aos parâmetros de altura, ritmo e dinâmica. Sua métrica é guiada pela fórmula de compasso 2/4 (binário simples), e por vezes alterada para 3/4 (ternário simples), mas imediatamente após poucos compassos restabelece o binário simples por longos períodos. Além disso, Kiefer propõe alterações de andamentos em Notas Irresponsáveis. A obra inicia com indicação de “Andamento Firme" com semínima igual a 84. As alterações ocorrem nos inícios

3 Usamos o termo "2 depois de 60 " porque a partitura que tivemos acesso contém erros na marcação de números de compasso. Entre os números 60 e 110 há equívocos de numeração. Dessa forma, optamos por adotá-los como referência de local e não como contagem de compasso. A partir do número 110 a contagem está correta. Sendo assim, tudo que estiver entre os números 60 e 110 destacamos com "antes de" e/ou "depois de". A partir de 110, destacamos como números de compassos. 
MUSICA THEORICA Revista da Associação Brasileira de Teoria e Análise Musical 2019, v. 4, n. 1, p. 255-279-Journal of the Brazilian Society for Music Theory and Analysis@ TeMA 2019 - ISSN 2525-5541

dos cânones, onde a indicação solicita "um pouco mais lento" com semínima igual a 76 e retomando o "tempo I" ao término do episódio (apenas no primeiro cânone), e na região $f$ (6 depois de 100 - c. 116), onde há uma solicitação de "Lento" com semínima igual a 66 e retomada de "tempo I" após conclusão da região até o final da peça.

Kiefer explora dois tipos de textura em Notas Irresponsáveis: homofônica e polifônica. Berry (1987) afirma que

homofonia literalmente denotaria uma condição de interdependência das vozes, mas sua conotação tradicional é de textura na qual uma voz primária é acompanhada por um tecido subordinado algumas vezes interativo de maneira provisória, o baixo normalmente em direção contrária ou em outra relação contrapontística com a voz (ou vozes) principal (Berry 1987, p. 192).

Hyer (2001) define homofonia como "música polifônica na qual as vozes se movem juntas mais ou menos no mesmo ritmo" (Hyer 2001, s.p.). Kiefer explora fortemente esta textura (partes que seguem no mesmo ritmo) na região a (c. 1-11), por vezes a três vozes, mas frequentemente a duas vozes. Além disso, pequenas inserções homofônicas ocorrem em diferentes regiões temáticas e em momentos de transição, como, por exemplo, o final do segundo cânone. A região $f$ (6 depois de 100 - c. 116) é inteiramente nessa textura, assim como a grande parte da região a' (c. 117-129), agora em caráter de recapitulação.

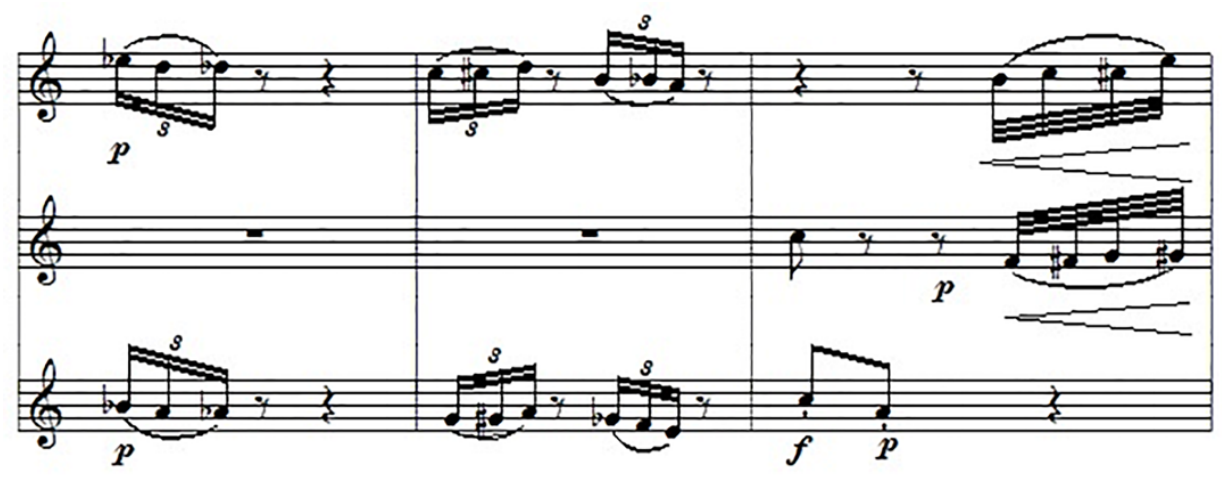

Exemplo 1a: Notas Irresponsáveis c. 4-6, homofonia 
PRATES, V. D. Elementos melódicos e harmônicos recorrentes em Notas Irresponsáveis de Bruno Kiefer: uma abordagem Pós-Tonal
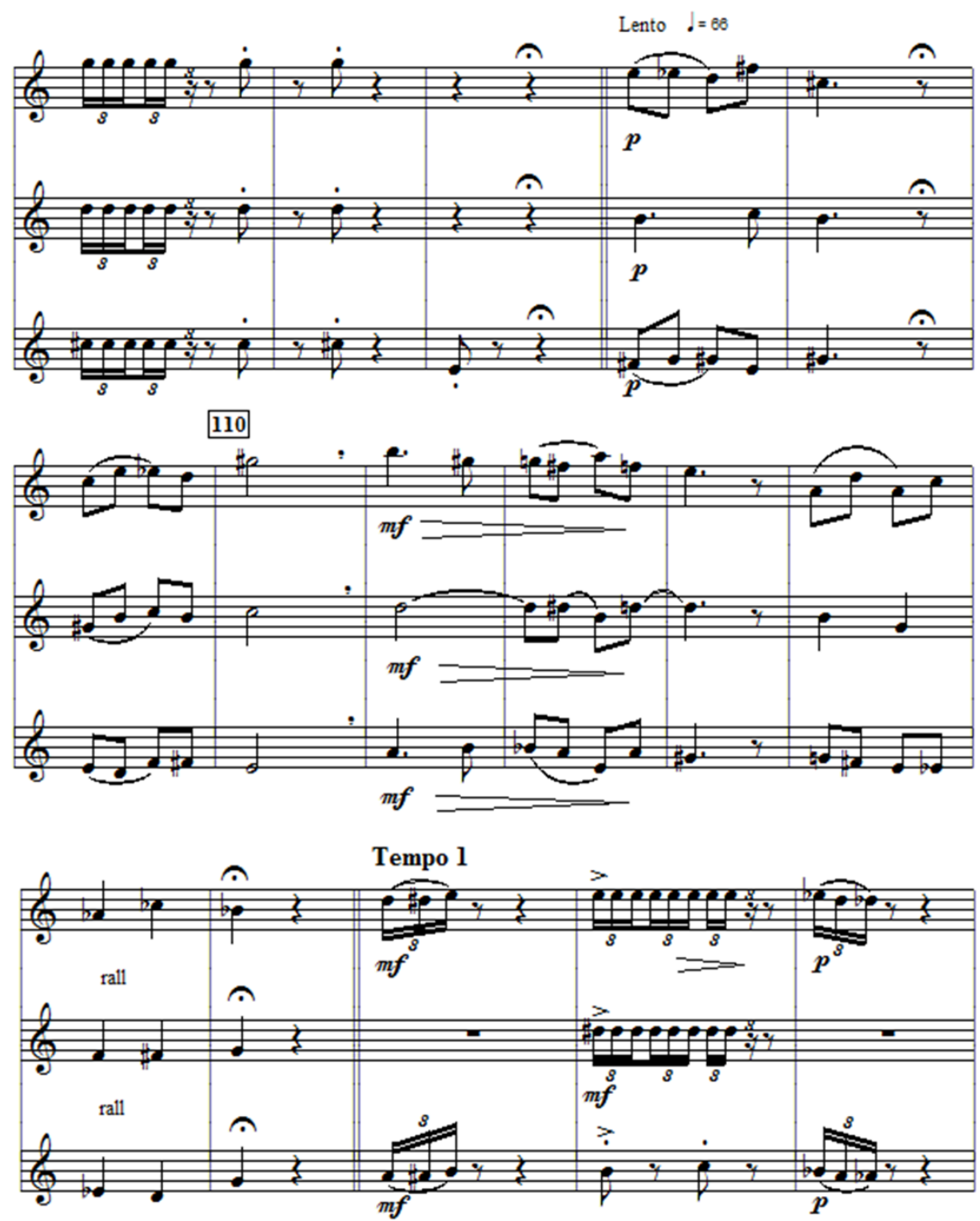

Exemplo 1b: Notas Irresponsáveis. 6 antes de 100-1204 (transição do segundo cânone para região f em "Lento" e início da Seção C em "tempo I"), homofonia

Frobenius, Cooke e Bithell (2001) definem polifonia como "música em mais de uma parte, música em muitas partes, estilo na qual todas ou a maioria das partes da música se movem de forma independente" (Frobenius; Cooke; Bithell 2001, s.p.). Kiefer explora esse recurso de duas maneiras distintas em Notas Irresponsáveis:

\footnotetext{
${ }^{4}$ Ver nota anterior.
} 
MUSICA THEORICA Revista da Associação Brasileira de Teoria e Análise Musical 2019, v. 4, n. 1, p. 255-279-Journal of the Brazilian Society for Music Theory and Analysis@ TeMA 2019 - ISSN 2525-5541

1) como forma de diálogo entre as vozes, passando fragmentos motívico/melódicos de voz para voz, dando uma ideia de conexão e continuidade de fraseado (Ex. 2a);

2) como contraponto de vozes em imitação nos cânones (Ex. 2b).

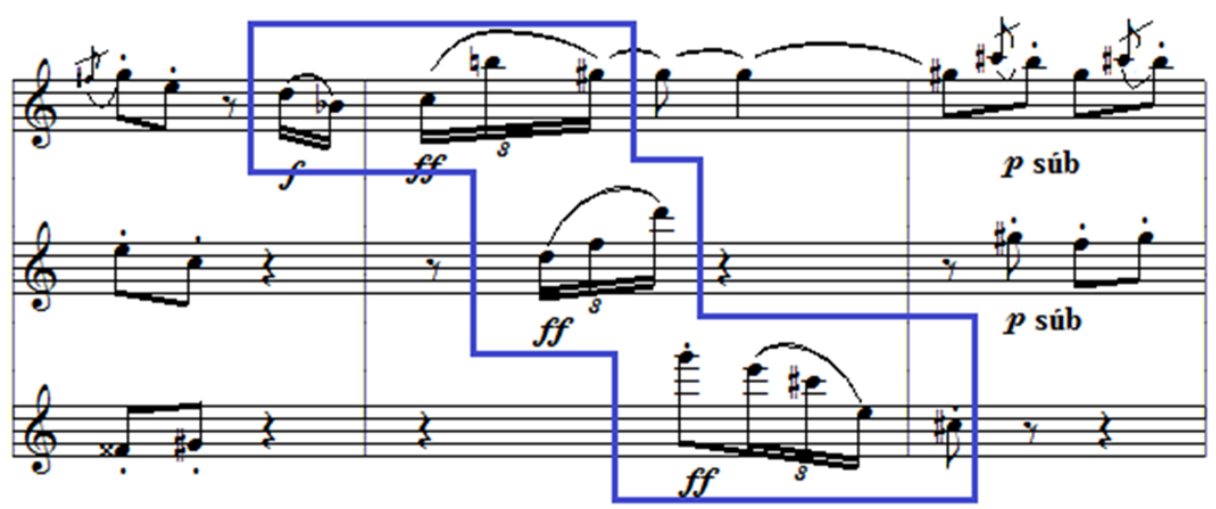

Exemplo 2a: Notas Irresponsáveis c. 22-24. Fragmentos melódicos que passam de voz para voz
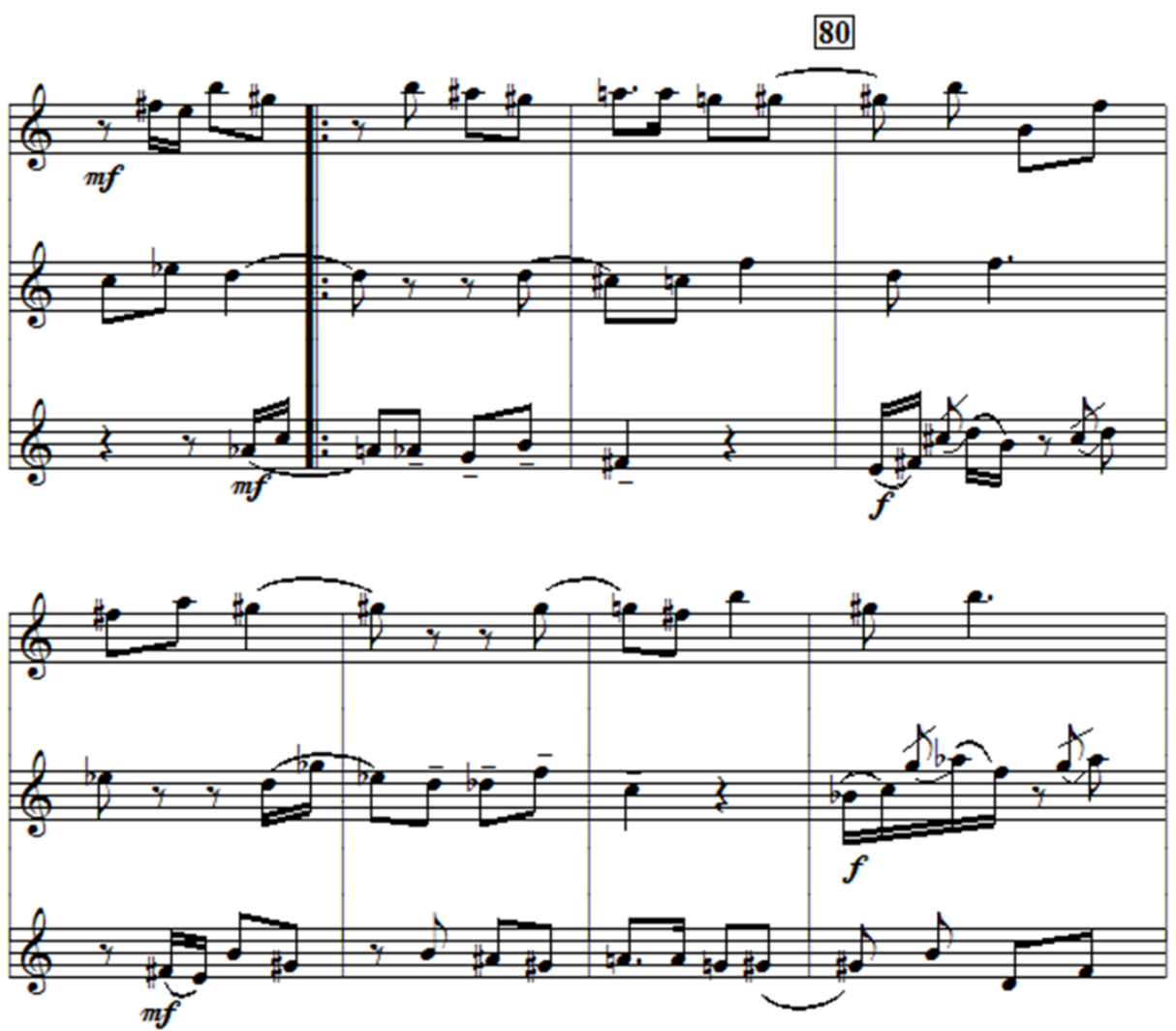

Exemplo 2b: Notas Irresponsáveis (segundo cânone) 3 antes de 80 a 4 depois de 80 . Imitação 
PRATES, V. D. Elementos melódicos e harmônicos recorrentes em Notas Irresponsáveis de Bruno Kiefer: uma abordagem Pós-Tonal

Kiefer insere dois pequenos solos na terceira flauta. Estes eventos ocorrem nas transições que antecedem os dois cânones e em um momento de contraste textural da região c (c. 29-52) (ver Ex. 3a e 3b).

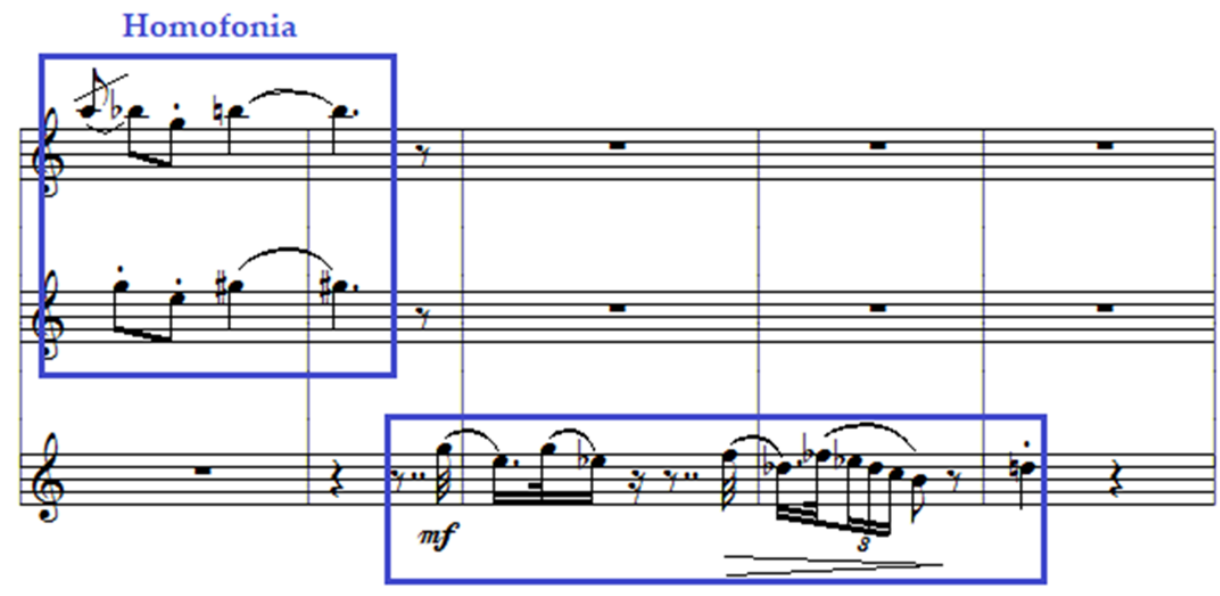

Solo na terceira voz

Exemplo 3 a: Notas Irresponsáveis c. 35-39. Pequeno solo na terceira voz

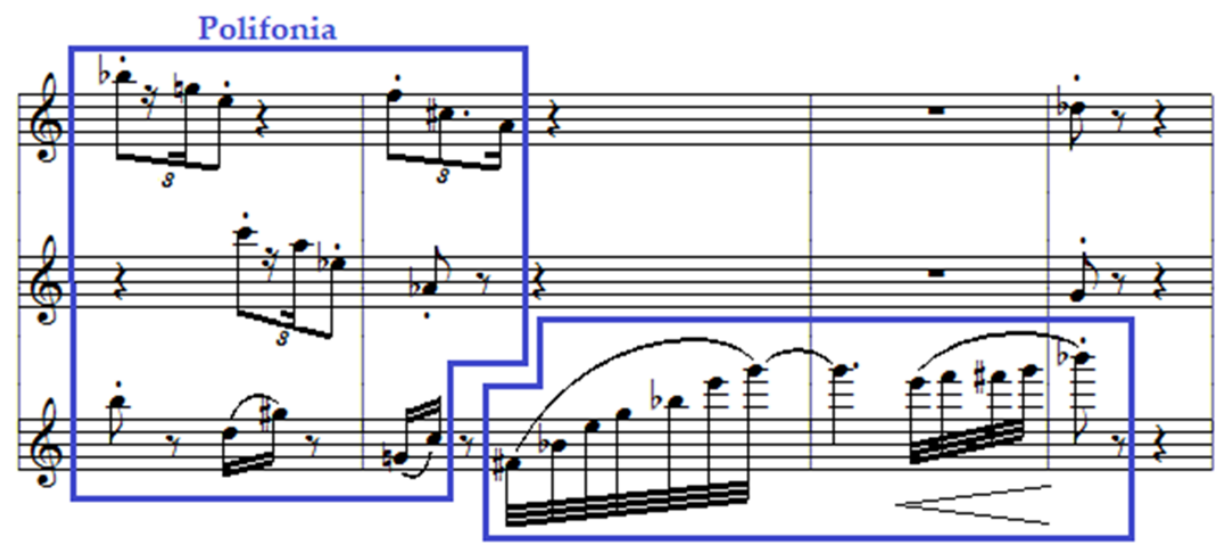

Solo na terceira voz

Exemplo 3b: Notas Irresponsáveis c. 45-48. Pequeno solo na terceira voz

Para a compreensão melódica e harmônica segundo a Teoria Pós-Tonal foi necessário um estudo de identificação de conjuntos. Nosso critério para a delimitação desses conjuntos se baseou na observação de como o compositor organiza seu material temático. Verificamos recorrência de ideias musicais curtas, abruptamente interrompidas por pausas, bem como ideias musicais curtas e isoladas com ritmos contrastantes a ideias anteriores e posteriores. Suas durações variam de um tempo a três compassos. Dessa forma, delimitamos 
MUSICA THEORICA Revista da Associação Brasileira de Teoria e Análise Musical 2019, v. 4, n. 1, p. 255-279-Journal of the Brazilian Society for Music Theory and Analysis@ TeMA 2019 - ISSN 2525-5541

conjuntos de notas que devem ser entendidos como o material melódico e harmônico trabalhado por Kiefer.

Além disso, o aspecto textural a três vozes teve de ser considerado. $\mathrm{Na}$ textura homofônica, os conjuntos foram interpretados de forma vertical e em blocos como em estudos de harmonia (Ex. 4a). Na textura polifônica adotamos dois critérios: vertical e horizontal. Os polifônicos verticais ocorrem quando há independência do movimento das vozes, mas fragmentos melódicos são passados de voz para voz com sensação de continuidade (vide Ex. 4b). Os polifônicos horizontais ocorrem apenas nos cânones e se assemelham ao estudo de contraponto, onde se leva em consideração a linha melódica (Ex. 4c).

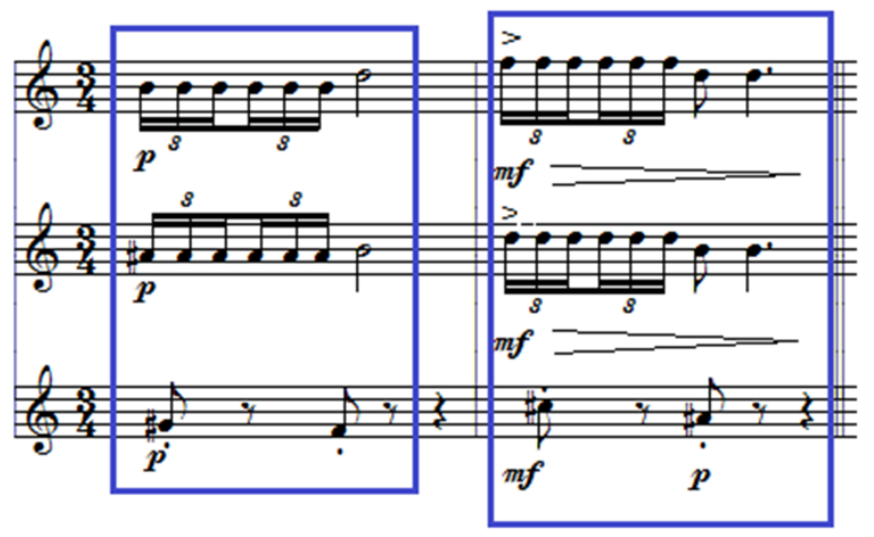

Exemplo 4a: Notas Irresponsáveis c. 15-16. Homofonia. Conjuntos verticais

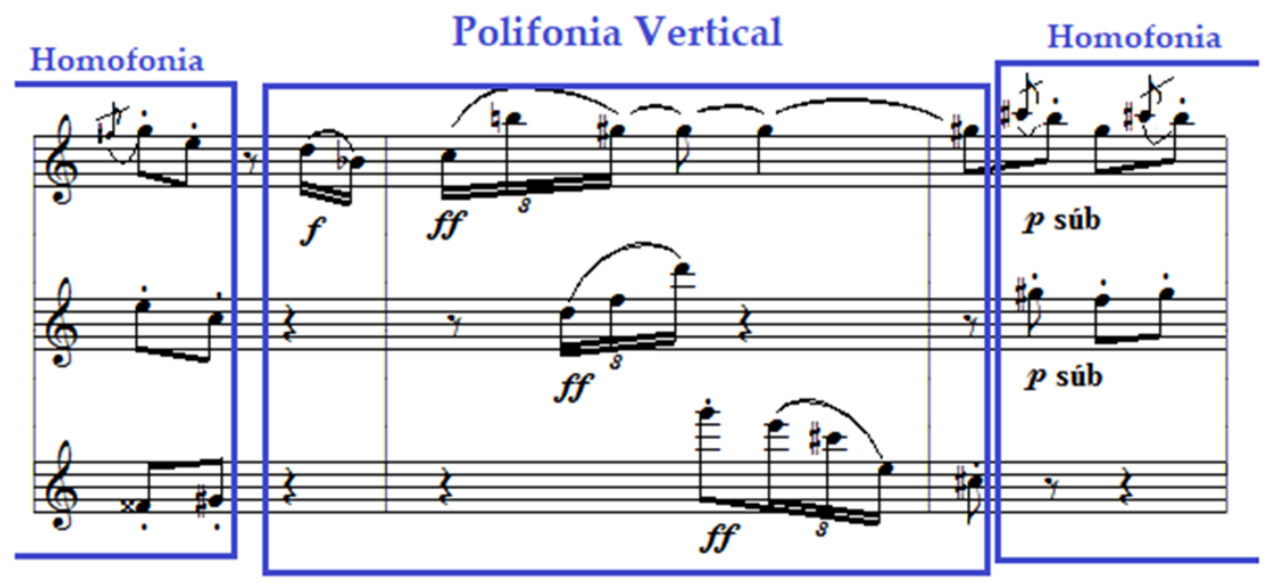

Exemplo 4b: Notas Irresponsáveis c. 22-24. Polifonia vertical. Conjunto vertical 
PRATES, V. D. Elementos melódicos e harmônicos recorrentes em Notas Irresponsáveis de Bruno Kiefer: uma abordagem Pós-Tonal

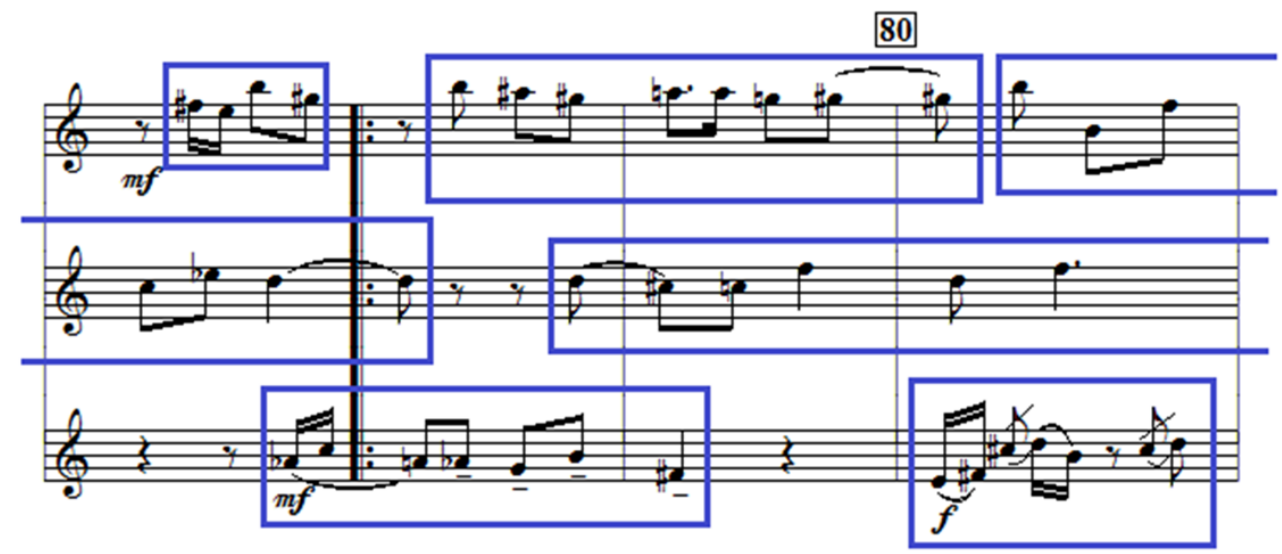

Exemplo 4c: Notas Irresponsáveis (segundo cânone) 3 antes de 80 a 80. Polifonia horizontal. Conjuntos horizontais

De acordo com nosso entendimento acerca dos elementos melódicos e harmônicos que compõem Notas Irresponsáveis, é possível notar a incidência de conjuntos octatônicos e cromáticos. Segundo Wilson (2001) a escala octatônica é um padrão simétrico formado pela intercalação de tons e semitons. Tal agrupamento gera na Teoria Pós-Tonal o conjunto de oitos sons [8-28], na classificação de Forte (1973), do qual podemos extrair subconjuntos de menor tamanho. Nessa classificação, o primeiro número indica a quantidade de sons presentes na coleção e o segundo a sua localização na listagem. Podemos considerar padrões octatônicos conjuntos de 3 a 8 sons. A Figura 1 apresenta os subconjuntos conforme nos mostra Gerling (2001):

[8-28]

\begin{tabular}{l}
\hline [7-31] \\
\hline$[6-27][6-30][6-Z 13][6-Z 23][6-Z 49][6-Z 50]$ \\
\hline$[5-10][5-16][5-19][5-28][5-31][5-32]$ \\
\hline$[4-3][4-9][4-10][4-12][4-13][4-17][4-18][4-25][4-26][4-27][4-28][4-Z 15][4-Z 29]$ \\
\hline$[3-2][3-3][3-5][3-7][3-8][3-10][3-11]$
\end{tabular}

Figura 1: Conjunto e subconjuntos octatônicos (Gerling 2001, p. 58)

Os conjuntos cromáticos são segmentos de sons em intervalos de semitons. São identificados na lista de Forte (1973) pelo número 1 ao final do nome conforme Figura 2:

$$
\text { [3-1] [4-1] [5-1] [6-1] [7-1] [8-1] }
$$

Figura 2: Conjuntos cromáticos 
MUSICA THEORICA Revista da Associação Brasileira de Teoria e Análise Musical 2019, v. 4, n. 1, p. 255-279-Journal of the Brazilian Society for Music Theory and Analysis @ TeMA 2019 - ISSN 2525-5541

Encontramos considerável recorrência de conjuntos octatônicos e cromáticos em Notas Irresponsáveis. Kiefer distribui esses conjuntos de forma equilibrada entre as regiões temáticas, dificultando a classificação de determinada região com características de determinado padrão. Existem regiões em que nenhuma dessas duas qualidades de conjuntos ocorre. Observa-se que a Seção A (c. 1-52) apresenta na região a (c. 1-11) apenas um conjunto cromático, 6 octatônicos na região $b$ (anacruse para c. 12-28) e um octatônico e 6 cromáticos na região c (c. 29-52). Essas alterações de padrões melódicos ocorrem paralelamente a alterações texturais.

A região a (c. 1-11), apesar de não classificada como octatônica ou cromática, apresenta conjuntos com características cromáticas, mas que não são assim classificados por alterações no padrão de semitons. Estes conjuntos chamaremos de pseudo-cromáticos, ou seja, agrupamentos com conteúdo cromático predominante, mas que, em determinado ponto de sua formação, apresentam algum intervalo que não se encaixe no padrão de sequência de semitons. Essa característica se manifesta já nos dois primeiros conjuntos da obra e em suas transposições. Os conjuntos [4-7] e [6-Z6] que possuem Formas Primas (0 14 5) e (0 1256 7), respectivamente, têm qualidades cromáticas embora sejam interrompidas por um salto de segunda aumentada em [4-7] e de terça menor (Classe de Intervalo 3) em [6-Z6] situados em suas regiões centrais, fato que, inclusive, os transforma em simétricos e similares entre si. O Exemplo 5 exibe esses conjuntos em suas Formas Normais da primeira aparição.

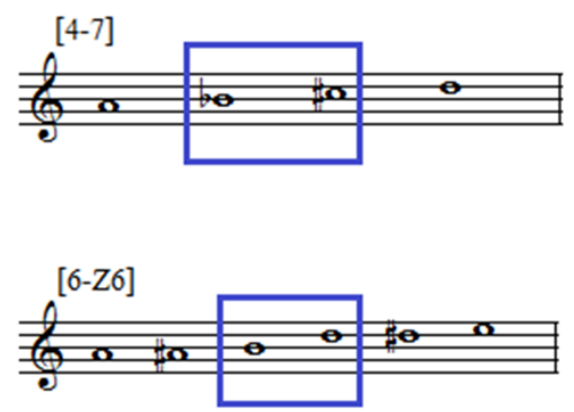

Exemplo 5: Conjuntos pseudo-cromáticos [4-7] e [6-Z6] em suas Formas Normais. Qualidades cromáticas interrompidas por saltos de segunda aumentada e terça menor (Classe de Intervalo 3), respectivamente 
PRATES, V. D. Elementos melódicos e harmônicos recorrentes em Notas Irresponsáveis de Bruno Kiefer: uma abordagem Pós-Tonal

A Classe de Intervalo 3 é elemento que merece destaque conforme será mostrado nesta análise de Notas Irresponsáveis. Aqui, o intervalo se insere no meio da sonoridade cromática. A ocorrência dos conjuntos [9-4] e [6-2], que possuem Formas Primas (0 1234578 9) e (0 1234 6), embora não totalmente cromáticos com seus padrões interrompidos por uma ocorrência de intervalo de segunda maior em cada um, reforça a sonoridade mais aproximada à cromática da região $a($ c. 1-11).

A região b (anacruse para c. 12-28), apesar de ter uma maior recorrência de padrões octatônicos, apresenta uma característica mista em seus padrões melódicos devido à inserção de alguns conjuntos pseudo-cromáticos como, por exemplo [9-10], [8-Z15] e [9-2] que possuem Formas Primas (0 1234679 10), (0 123468 9) e (0 1234567 9), respectivamente. A região c (c. 29-52), além de possuir maior indício cromático total pela utilização frequente do conjunto [3-1], Forma Prima (0 12 ), tem essa característica reforçada pela utilização dos conjuntos pseudo-cromáticos [8-13] e [4-5] com Formas Primas (0 1223467 9) e (0 12 6 6), respectivamente, além da ocorrência do conjunto (0 12345789 10) (mostrado aqui em sua Forma Prima) $)^{5}$, que possui quase que na sua totalidade intervalos de semitons.

Os cânones, compreendendo as regiões $d$ (anacruse para c. 53-62) e $d^{\prime}$ (anacruse para 11 depois de 60-5 depois de 100), são compostos de material melódico mais variado que a Seção $A$ (c. 1-52). Aqui ocorrem padrões cromáticos como [5-1], pseudo-cromáticos como [6-Z3], Forma Prima (0 102356 e octatônicos como [6-27], bem como conjuntos de características mais diatônicas e tonais. Ao analisarmos os conjuntos [5-23] (primeiramente utilizado na Forma

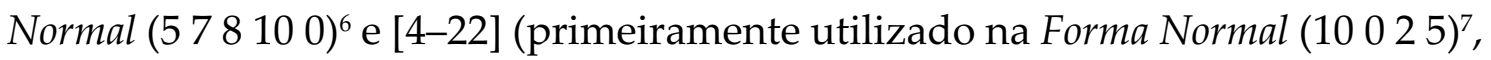
vemos que Kiefer explora sonoridades diferentes daquelas reforçadas anteriormente. O Exemplo 6 apresenta [5-23] e [4-22] em suas Formas Normais através de notação tradicional para uma melhor visualização.

\footnotetext{
${ }^{5}$ Este conjunto não possui nome na classificação de Forte (1973) por apresentar mais de 9 sons.

${ }^{6}$ Forma Prima (0 2357 ).

${ }^{7}$ Forma Prima (0 24 7).
} 

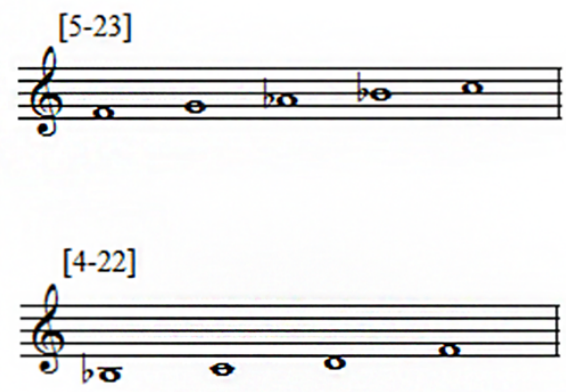

Exemplo 6: Conjuntos [5-23] e [4-22] em suas Formas Normais. Características diatônicas

Sob uma ótica tradicional tonal, o conjunto [5-23] pode ser entendido como um seguimento da escala de Fá menor. Portanto, aqui há uma interpretação diatônica. O conjunto [4-22] devido a um salto de terça menor entre seu terceiro e quarto graus, aumenta sua possibilidade de interpretação em um viés tonal. Este agrupamento pode ser inserido dentro das possibilidades de Fá menor melódico, Fá Maior, Si, Maior, entre outros, bem como ser entendido como segmento de uma escala pentatônica. No entanto, a abordagem Pós-Tonal não nos permite classificar esses conjuntos dessa forma, embora, como sonoridade, eles possam transmitir uma impressão de variação de padrões melódicos. Tendo em vista que todos os conjuntos dos cânones são submetidos a transposições e repetições, é possível afirmar que as sonoridades "diatônicas" exploradas por Kiefer enriquecem o material melódico da obra.

A região $f$ (6 depois de 100 - c. 116), apesar de não apresentar conjuntos inteiramente cromáticos, é composta por apenas quatro formações, todas pseudo-cromáticas. Os critérios de delimitação dos conjuntos aqui, como explicado anteriormente, se deram de forma vertical, respeitando os blocos sonoros a três vozes em suas respirações e cadências. Contudo, ao observarmos o movimento melódico das vozes individualmente, percebemos que essas se movem com alto índice de cromatismo. Dessa forma, afirmamos que a região $f$ é cromática.

Além da análise acerca de conjuntos e suas diferentes formações e utilizações por Kiefer, devemos dar atenção também a suas preferências intervalares, tanto de forma harmônica como melódica. Para isso, voltaremos às regiões canônicas de Notas Irresponsáveis. Mann, Wilson e Urguhart (2001) definem cânone como uma forma polifônica de execução musical na qual um performer executa uma ou mais linhas melódicas derivadas de uma dada 
melodia, a qual será imitada a uma distância de tempo e intervalo. Em seu trio de flautas, Kiefer opta pela prática menos frequente e constrói seus cânones com variações intervalares (ou seja, transposições) entre as vozes que realizam a imitação. Os conjuntos que iniciam as regiões canônicas são [6-Z3], [5-23] e [422] e aparecem nas Formas Normais (0 1235 6), (5 7810 0) e (10 02 5). Apesar de serem apresentados em nossa delimitação de conjuntos como três entidades diferentes e separadas, aqui devem ser entendidos como sequenciais, assumindo um sentido melódico e temático único. Esses três conjuntos formam a primeira melodia do cânone a ser imitada. Essa imitação ocorre transposta, gerando as Formas Normais (6 78911 0), (11 1246 ) e (4 6811$)$. Ao analisarmos a transposição é possível notar que a distância que separa os primeiros conjuntos dos demais é de 6 semitons (Classe de Intervalo 6), o que na Teoria Pós-Tonal corresponde à fórmula $\mathrm{T}_{6}{ }^{8} \mathrm{O}$ Exemplo 7 ilustra os conjuntos e suas transposições através de notação tradicional.

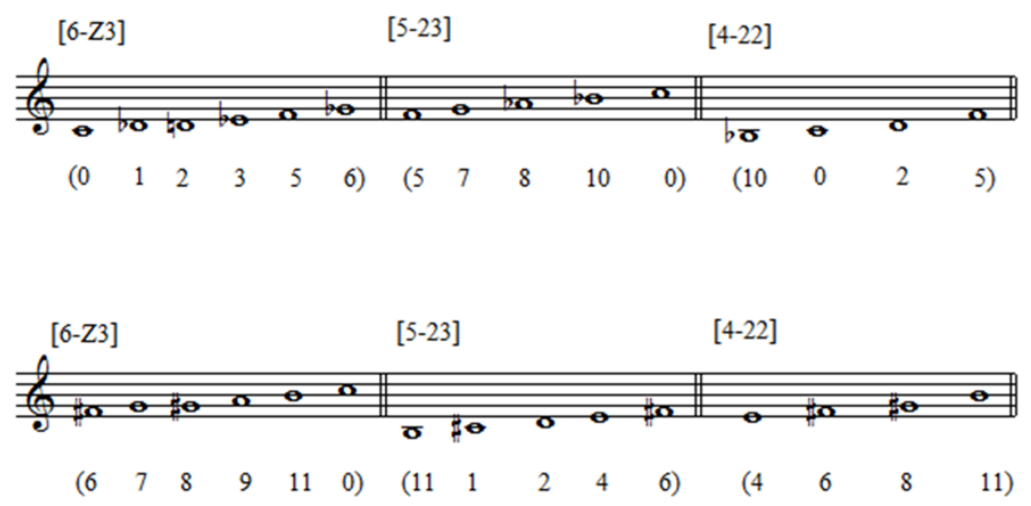

Exemplo 7: Conjuntos[6-Z3], [5-23] e [4-22] transpostos à Classe de Intervalo 6

Essa transposição domina na totalidade as regiões canônicas de tal modo que todos os conjuntos são alterados em 6 semitons. Contudo, sob a ótica desta constante, Kiefer teria cometido um equívoco transpondo uma nota da primeira flauta a uma distância de 3 semitons ao invés de 6 (ver nota Si grave destacada no Ex. 8c). A melodia correspondente a esta transposição apresenta a nota Láb em sua primeira exposição no primeiro Cânone (ver nota Láb destacada no Ex. 8a).

\footnotetext{
${ }^{8}$ Fórmula Tn. A letra $T$ significa Transposition (transposição) e a letra $n$ significa o número de semitons em que se deu a transposição. Deve-se levar em consideração o ciclo de 12 semitons para o cálculo correto.
} 
MUSICA THEORICA Revista da Associação Brasileira de Teoria e Análise Musical 2019, v. 4, n. 1, p. 255-279-Journal of the Brazilian Society for Music Theory and Analysis@ TeMA 2019 - ISSN 2525-5541

Na segunda região canônica, a mesma melodia apresentada na segunda flauta ainda sem transposição, reaparece inalterada, nos levando a crer que a forma original está correta pois Kiefer a repete Ipsis litteris (Ex. 8b). Uma vez que todos os conjuntos são transpostos a uma distância de 6 semitons nas regiões canônicas, a alteração correta nesta melodia reapresentada na primeira flauta deveria ser para nota Ré (6 semitons de Lá)) ao invés de Si (3 semitons de Láb), conforme Exemplo 8d.

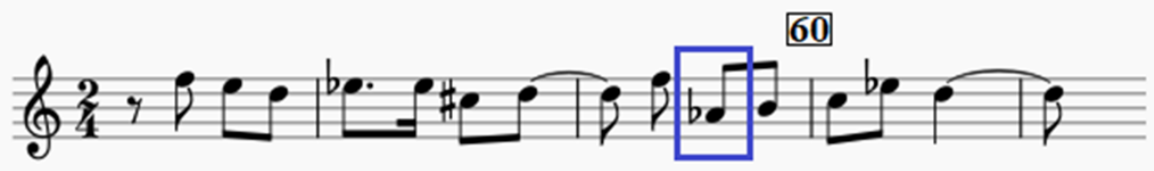

Exemplo 8a: Notas Irresponsáveis (segunda flauta) c. 57 a 1 depois de 60. Primeira exposição da melodia no primeiro Cânone

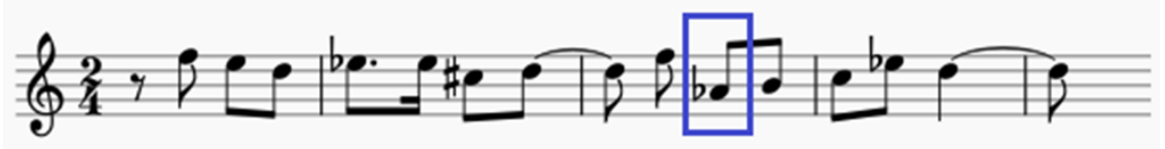

Exemplo 8b: Notas Irresponsáveis (segunda flauta) 6 antes de 80 a 2 antes de 80 . Reapresentação ipsis litteris da melodia no segundo Cânone

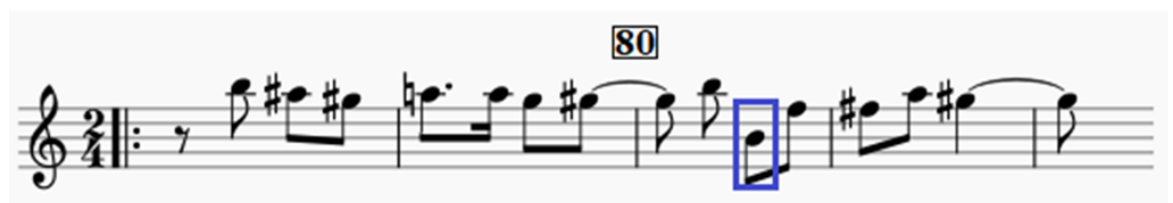

Exemplo 8c: Notas Irresponsáveis (primeira flauta) 2 antes de 80 a 2 depois de 80. Transposição com nota equivocada

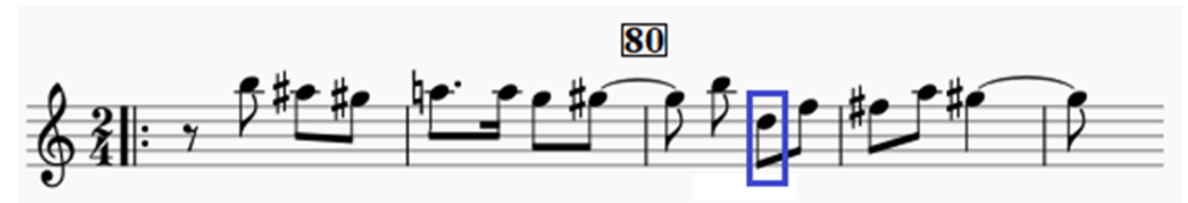

Exemplo 8d: Notas Irresponsáveis (primeira flauta) 2 antes de 80 a 2 depois de 80. Transposição correta. 
PRATES, V. D. Elementos melódicos e harmônicos recorrentes em Notas Irresponsáveis de Bruno Kiefer: uma abordagem Pós-Tonal

Chama a atenção que o compositor constrói a imitação baseada na Classe de Intervalo 6, que na teoria tradicional é conhecido como trítono, intervalo dissonante e instável. Além do cânone, outras duas utilizações desse intervalo merecem destaque, ambas relacionadas a alterações de textura e/ou seção. A primeira ocorre entre os dois cânones e possui textura homofônica em forma de coral, antecedendo uma breve região polifônica. $\mathrm{O}$ fato ocorre no modo como o compositor distribui os sons do conjunto [4-28] (Forma Prima (0 36 9 9)) à duas vozes, destacando de forma harmônica dois trítonos (Ex. 9a). Também devemos considerar que o conjunto [4-28], em harmonia tradicional, é uma tétrade diminuta, ou o acorde de sétima diminuta. A segunda utilização que destacamos ocorre na Coda (c. 130-134), em textura polifônica e com caráter melódico (ver Ex. $9 b)$. Chama a atenção aqui a impressão de grande instabilidade que o intervalo agrega ao final da peça.

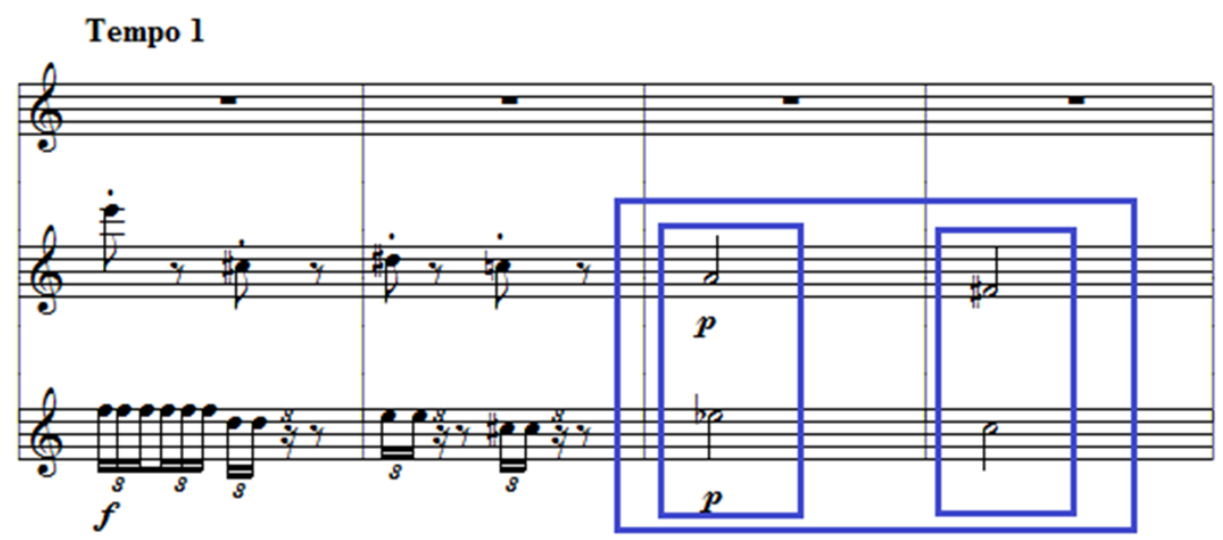

Exemplo 9a: Notas Irresponsáveis. 2 depois de 60 a 5 depois de 60. Utilização do trítono (Classe de Intervalo 6) harmônico

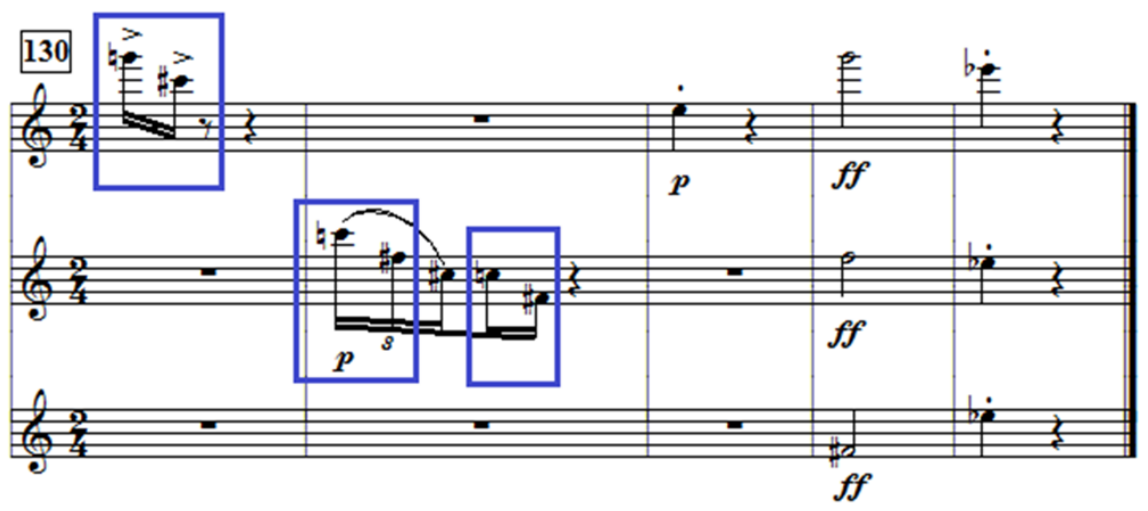

Exemplo 9b: Notas Irresponsáveis c. 130-134. Utilização do trítono (Classe de Intervalo 6) melódico 
MUSICA THEORICA Revista da Associação Brasileira de Teoria e Análise Musical 2019, v. 4, n. 1, p. 255-279-Journal of the Brazilian Society for Music Theory and Analysis @ TeMA 2019 - ISSN 2525-5541

Na música tradicional a relação do trítono (aqui vista como Classe de Intervalo 6) com formações diminutas, tanto tríades como tétrades, é muito comum. Nesses casos, normalmente encontramos agrupamentos de terças menores (aqui vista como Classe de Intervalo 3). Dessa forma, entendemos que é possível estreitar as relações entre essas duas Classes de Intervalos como associadas uma a outra. Lembramos que a tríade diminuta é uma superposição de duas terças menores, portanto existe uma proximidade de identidade intervalar.

Logo no início de Notas Irresponsáveis Kiefer utiliza a Classe de Intervalo 3 como elemento cadencial de forma melódica na região grave da flauta transversal. Outra utilização do intervalo que daremos destaque se manifesta de maneira similar à adotada pelo compositor conforme exemplificado no Exemplo 9a. Nessa situação é utilizado o conjunto [5-16] em Forma Normal (10 1112 5), sendo destacadas três possibilidades de configurações sonoras em Classe de Intervalo 3:

- Kiefer separa a primeira e segunda vozes à distância de terça menor, movendo as vozes de forma paralela;

- a terceira voz não forma terça menor com outras vozes, embora seu movimento melódico apresente o intervalo;

- as três vozes se movimentam explorando a Classe de Intervalo 3 (Ex. $10)$.

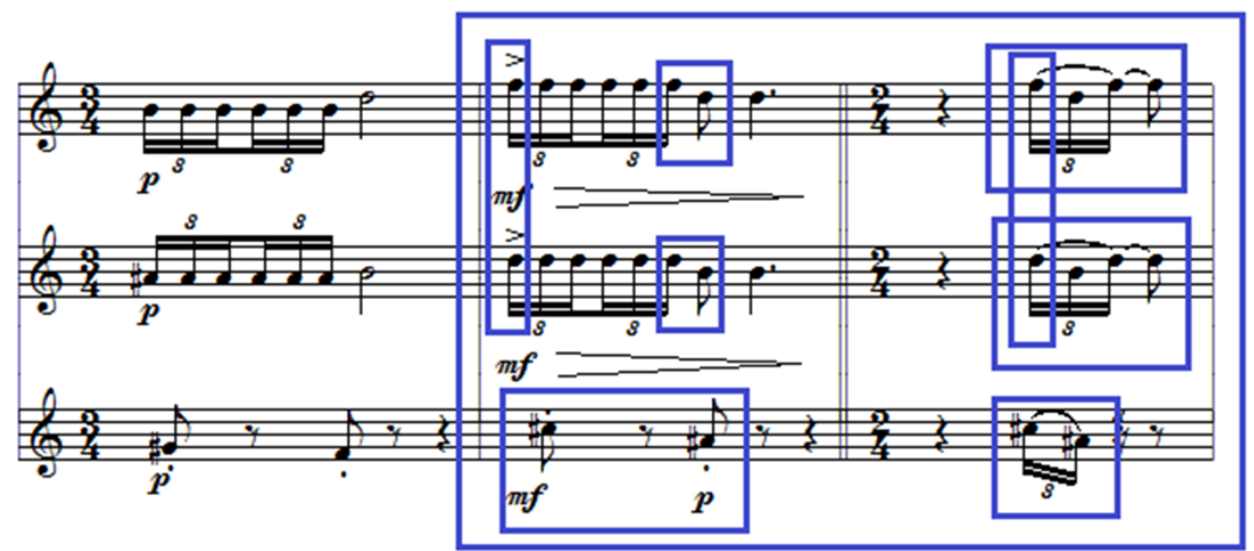

Exemplo 10: Notas Irresponsáveis c. 15-17. Utilização da terça menor (classe de intervalo 3) 
PRATES, V. D. Elementos melódicos e harmônicos recorrentes em Notas Irresponsáveis de Bruno Kiefer: uma abordagem Pós-Tonal

\section{Discussão: paralelo entre Notas Irresponsáveis (1986/87) e a literatura}

Em comparativos com a literatura analítica sobre a obra de Kiefer, é possível verificar afinidades de nossos resultados com trabalhos de Gerling (2001) e Mayer (2005). Conforme Gerling (2001) o componente octatônico através de [8-28] e seus subconjuntos é elemento de presença inequívoca nas peças para piano Terra Selvagem, Lamentos da Terra e Alternâncias. Segundo observação conclusiva da autora, "dos subconjuntos ordenados, [4-28], ou seja, o acorde diminuto propriamente dito, é o que tem sua presença definidora mais frequente, bem como [5-25], [5-19] e [4-27]" (Gerling 2001, p.69). Dentre os agrupamentos citados, apenas [5-25] não ocorre em Notas Irresponsáveis. Todos os outros recorrentes são octatônicos. A autora ainda destaca outros conjuntos de diferentes coleções, todos com ocorrência no trio de flautas: [4-10], [4-3] e [3-10]. Sobre esses grupos Gerling (2001) afirma que

ainda que estes subconjuntos de quatro e três sons pertençam a várias outras coleções, a interpretação octatônica é mais condizente com seu contorno característico e com a frequência de ocorrência (Gerling 2001, p. 69).

Mayer (2005) também traz em sua conclusão resultados que vão ao encontro de dados que obtivemos em Notas Irresponsáveis. Segundo o autor, "encontram-se os subconjuntos da coleção octatônica na maior parte do grupo de peças investigadas" (Mayer 2005, p. 81). O autor ainda reforça a "presença variada de subconjuntos de [8-28]" (Mayer 2005, p. 81). Apesar de [8-28] não ocorrer na obra que analisamos, a sonoridade característica desses grupos se sobressai em determinadas regiões temáticas e pontos específicos do trio de flautas. Entre os agrupamentos que Mayer (2005) destaca e que também ocorrem em Notas Irresponsáveis estão os octatônicos [3-3], [4-3] e [4-17] e o cromático [4$1]$.

Apesar de os conjuntos com características diatônicas encontrados na obra que investigamos não possuírem incidência significativa a ponto de serem considerados elementos preferenciais de Kiefer, devemos observar que suas ocorrências se assemelham a resultados de pesquisas anteriores. Mayer (2005) analisa que tríades de Quadro $\mathrm{n}^{\circ} 3$

compõem-se de configurações intervalares que vão ao encontro da coleção octatônica. No entanto, observa-se no início da peça um fragmento de ciclo 
MUSICA THEORICA Revista da Associação Brasileira de Teoria e Análise Musical 2019, v. 4, n. 1, p. 255-279-Journal of the Brazilian Society for Music Theory and Analysis@ TeMA 2019 - ISSN 2525-5541

de quintas dando a esses acordes um viés tonal, o que é logo eliminado (Mayer 2005, p. 80).

O autor ainda destaca a "presença tanto de tríades como de outros elementos diatônicos em meio a disposições claramente atonais. Assim, disponibiliza uma vasta gama de possibilidades ao compositor" (Mayer 2005, p. $81)$.

Embora Mayer (2005) não tenha citado conjuntos, suas afirmações mostram que há tendências sonoras tonais e diatônicas em dados momentos de determinadas peças de seu repertório, apesar de a característica de sonoridade não assumir um papel decisivo tonal/diatônico. Como vimos, foram identificados conjuntos em Notas Irresponsáveis que podem ser interpretados como segmentos de escala de uma determinada tonalidade. Assim como ocorre em Mayer (2005), essas sonoridades tonais surgem em momentos isolados na peça para flautas, sem que se tornem predominantes em alguma região ou sessão, mas enriquecendo o material melódico empregado por Kiefer.

Mayer (2005) comenta que, entre o repertório analisado por ele, “a $3^{\text {a }}$ Menor, neste conjunto de peças, também se apresentou como um gesto de autocitação" (Mayer 2005, p. 88). Com essa afirmação, o autor nos mostra a recorrência deste intervalo, fato que vai ao encontro de dados que obtivemos a partir da análise de Notas Irresponsáveis. A autocitação comentada pelo autor aproxima a linguagem da peça que analisamos a características já estudadas e identificadas em outras pesquisas sobre a obra de Kiefer, conforme veremos adiante.

As proximidades mais significativas entre a obra para flauta transversal abordada nesse artigo e os resultados de Gerling (2001) e Mayer (2005) ocorrem através dos subconjuntos de [8-28]. Igualmente, outros conjuntos de diferentes naturezas também se mostraram recorrentes entre nossos resultados e os desses autores. Dentre tais conjuntos destacamos o octatônico [4-28] que também possui forte relação com a terça menor por ser uma tétrade diminuta.

Além disso, a superposição de terças menores gera os conjuntos [3-10] e [4-28] (diminutos) que trazem consigo outro intervalo preferencial de Kiefer: o trítono. Verificamos que o compositor explora esse material, a exemplo da terça menor, tanto de forma melódica como harmônica. A relação que se estabelece entre esses intervalos pode ser entendida através de suas instabilidades, sendo a terça menor uma consonância imperfeita e o trítono uma dissonância. 
PRATES, V. D. Elementos melódicos e harmônicos recorrentes em Notas Irresponsáveis de Bruno Kiefer: uma abordagem Pós-Tonal

Acreditamos que a insistência de Kiefer nessas sonoridades é um dos fatores que contribuem para sua proposta estética de conflito e tensão presentes em Notas Irresponsáveis.

Apesar de o intervalo terça menor estar por vezes inserido entre os conjuntos pseudo-cromáticos como elemento de quebra do padrão de sucessão de semitons, não raro sua percepção fica diluída em meio aos desenhos melódicos construídos por Kiefer. Tais conjuntos em alguns momentos estão presentes em determinadas regiões temáticas como sonoridades únicas ou predominantes. Associando-se a grande recorrência de conjuntos totalmente cromáticos que verificamos em Notas Irresponsáveis, é possível afirmar que o compositor explora o cromatismo independente da qualidade do conjunto como um de seus principais materiais temáticos. Acreditamos que essa característica é outro ponto que reforça sua proposta estética de conflito e tensão. Da mesma forma, a rotatividade de padrões cromáticos, octatônicos e, embora raros, diatônicos, além de enriquecer o material melódico e harmônico da composição, gera também, através de seus contrastes, elemento na interrupção do discurso, característica estilística de Kiefer.

Para Cardassi (1998) a autocitação é uma estratégia composicional de Kiefer. A autora classifica essa recorrência de ideias musicais como um enfoque analítico não explorado até então acerca do estilo do compositor. Acrescenta ainda que

só a reflexão analítica sobre peças de diversos gêneros e instrumentações possibilita mostrar que, em Kiefer, a estratégia composicional envolve a reutilização de ideias musicais idênticas que transitam de peça para peça (Cardassi 1998, p. 140).

Em outra pesquisa a autora comenta que

Através do processo de autocitação, Kiefer investe esse conjunto de peças ${ }^{9}$ de um alto nível de redundância composicional, o que confere um caráter unitário ao conjunto de peças e denota o pensamento consistente do compositor (Cardassi 2004, p. 26).

Neste artigo, procuramos traçar comparativos que aproximem a obra que escolhemos das características destacadas na literatura analítica sobre $o$

\footnotetext{
${ }^{9}$ Cardassi (2004) investiga peças de diferentes formações instrumentais compostas entre 1970 e 1983.
} 
MUSICA THEORICA Revista da Associação Brasileira de Teoria e Análise Musical 2019, v. 4, n. 1, p. 255-279-Journal of the Brazilian Society for Music Theory and Analysis @ TeMA 2019 - ISSN 2525-5541

compositor. Entendemos que as compatibilidades de conjuntos mostradas anteriormente são indícios da aproximação que buscamos. Com relação à autocitação, a observação de Mayer (2005) sobre o intervalo de terça menor possuir característica de material reapresentado em diferentes obras do repertório de sua pesquisa nos traz outros indícios de que Notas Irresponsáveis possui familiaridade com outras composições de Kiefer por meio dessa estratégia de escrita.

\section{Conclusão}

A compreensão do material melódico e harmônico sob a ótica da Teoria Pós-Tonal necessita um estudo de relação dos sons entre si e, por isso, está atrelada à nossa interpretação de execução de Notas Irresponsáveis. Os critérios adotados e explanados no corpo deste artigo vão ao encontro do nosso entendimento de performance da composição, podendo ser divergentes a outros executantes.

Entretanto, mesmo com entendimento de caráter subjetivo sobre a interpretação musical, foi possível aproximar nossos resultados a conclusões obtidas por outros autores que investigaram o repertório de Kiefer. É inquestionável que em uma percepção diferente quanto à execução da obra poderia se fazer necessário outros métodos de investigação e acarretar em resultados distintos. Mesmo assim, a concordância que se averiguou entre o fruto de nossa análise e as observações de Mayer (2005) e Gerling (2001) são consideráveis pelo volume de informações compatíveis entre os trabalhos. Tal concordância ocorre ao cruzarmos resultados que obtivemos através de nossa investigação com os dados obtidos nas pesquisas de apoio, observando a recorrência de conjuntos, subconjuntos e tipos de formações iguais ou similares, em especial octatônicas.

Uma vez identificados conjuntos e subconjuntos similares entre si ou de mesma natureza fica claro ao intérprete a origem dos elementos, possibilitando a compreensão do material proposto pelo compositor. Assim, o fundamento teórico pode agregar coesão às escolhas interpretativas, permitindo que o executante interprete os elementos similares e contrastantes com sentido musical consciente. Acreditamos que os dados aqui explanados sobre a variedade e rotatividade dos conjuntos melódicos e harmônicos possam contribuir para que intérpretes possuam uma maior gama de informação e que os ajude a relacionar 
PRATES, V. D. Elementos melódicos e harmônicos recorrentes em Notas Irresponsáveis de Bruno Kiefer: uma abordagem Pós-Tonal

e executar esses materiais de forma mais fundamentada, tanto na obra focada aqui, quanto em outras composições de Bruno Kiefer.

\section{Referências}

1. Berry, Wallace. 1987. Structural functions in music. New York: Dover Publications, Inc.

2. Cardassi, Luciane. 1998. A música de Bruno Kiefer: "terra", "vento", "horizonte" e a poesia de Carlos Nejar. Dissertação de Mestrado em Música. Porto Alegre: Instituto de Música, UFRGS.

3. Cardassi, Luciane. 2004. Autocitação no processo composicional de Bruno Kiefer. Goiânia: Música Hodie, v. 4, n. 1, p. 11-27.

4. Forte, Allen. 1973. The Structure of Atonal Music. London, New Haven and London: Yale University Press.

5. Frobenius, Wolf; Cooke, Peter; Bithell, Caroline; Zemtsovsky, Izaly. 2001. Polyphony. Grove Music Online.

6. Gerling, Cristina Capparelli. 2001. Terra Selvagem, Lamentos da terra e Alternâncias: o componente octatônico nas últimas três peças para piano de Bruno Kiefer. Belo Horizonte: PerMusi Revista de Performance Musical, n. 4, p. 52-71.

7. Hyer, Brian. 2001. Homophony. Grove Music Online.

8. Kiefer, Bruno. 1986/87. Notas Irresponsáveis. Porto Alegre: manuscrito, partitura.

9. Mann, Alfred; Wilson, J. Kenneth; Urguhart, Peter. 2001. Canon. Grove Music Online.

10. Mayer, Germano G. 2005. Seis Pequenos Quadros (1981) de Bruno Kiefer: relações intervalares e outros parâmetros a partir da teoria dos conjuntos e gestos musicais. Dissertação de Mestrado em Música. Porto Alegre: Instituto de Artes, UFRGS.

11. Prates, Vinicius Dias; Winter, Leonardo Loureiro; Carvalho, Any Raquel. 2014. Recorrências rítmico-melódicas na produção composicional para flauta de Bruno Kiefer. Vitória: ABRAPEM, v. 1, n. 1, p. 388-393.

12. Prates, Vinicius Dias. 2015. Elementos melódicos e gestuais recorrentes em duas peças para flauta transversal de Bruno Kiefer: Notas Soltas e Notas Irresponsáveis. Dissertação de Mestrado em Música. Porto Alegre: Instituto de Artes, UFRGS.

13. Prates, Vinicius Dias. 2017. Elementos gestuais recorrentes em Notas Soltas para flauta transversal solo de Bruno Kiefer. Curitiba: Revista Vórtex, v. 5, n.1, p. 119. 
MUSICA THEORICA Revista da Associação Brasileira de Teoria e Análise Musical 2019, v. 4, n. 1, p. 255-279-Journal of the Brazilian Society for Music Theory and Analysis @ TeMA 2019 - ISSN 2525-5541

14. Prates, Vinicius Dias; WINTER, Leonardo Loureiro. 2018. Estudo sobre o aspecto gestual em Notas Irresponsáveis para trio de flautas transversais de Bruno Kiefer. Caderno de Resumos do V Simpósio Internacional de Música IberoAmericana. Manaus: UEA, p. 67-68.

15. Straus, Joseph N. 2005. Introduction to Post-Tonal Theory. $3^{\circ}$ ed. New Jersey: Prentice-Hall Upper Saddle River.

16. Wilson, Charles. 2001. Octatonic. Grove Music Online. 